\title{
Pediatric Day Case Surgery in Rural Medical Outreach Programs: Enugu Experience
}

\author{
Chukwubuike Kevin Emeka* \\ Pediatric Surgery Unit, Department of Surgery, Enugu State University Teaching Hospital, Nigeria \\ *Corresponding author: Chukwubuike Kevin Emeka, Department of Surgery, Enugu State University Teaching Hospital, \\ Enugu, Nigeria
}

\section{ARTICLE INFO}

Received: 幽 February 12, 2021

Published: 慧 February 22, 2021

Citation: Chukwubuike Kevin Emeka. Pediatric Day Case Surgery in Rural Medical Outreach Programs: Enugu Experience. Biomed J Sci \& Tech Res 34(1)2021. BJSTR. MS.ID.005500.

Keywords: Day Case; Enugu; Medical Outreach; Nigeria; Pediatric; Surgery

Abbreviations: NARD: National Association of Resident Doctors; MDCAN: Medical and Dental Consultant Association of Nigeria; CMDA: Christian Medical and Dental Association, CHAN: Christian Health Association of Nigeria; APHPN: Association of Public Health Physician of Nigeria

\section{ABSTRACT}

Background: Pediatric day case surgeries performed in the rural setting of medical outreach is of great benefit to the patients who could not have access to specialist pediatric surgical care. The purpose of study was to evaluate our experience in carrying out pediatric day case surgeries during medical outreaches in the rural settings of Enugu, south east Nigeria.

Methods: This was a retrospective study of children that had day case surgeries during medical outreach in the rural areas of Enugu, south east Nigeria, over a 5-year period. The patients' demographics, duration of symptoms, diagnosis, operative procedure performed, outcome of treatment and complications of treatment were evaluated.

Results: During the study period, a total of 108 cases of pediatric day case surgeries were performed which accounted for $58.7 \%$ of all medical outreach surgeries. There were $81(75 \%)$ males and 27 (25\%) females, with a male to female ratio of 3:1. The median age of the patients was 54 months with a range of $10-72$ months. The median duration of the lesions was 7 months. Herniotomy for inguinal hernia and hydrocele was the most common performed surgical procedure. All the surgeries were performed under general anesthesia. Outcome was good in most of the patients. Surgical site infection was the most common post-operative complication. There was no mortality.

Conclusion: Pediatric surgical outreach programs offer opportunity for the treatment of surgical lesions of children in the rural areas who do not have access to specialist pediatric surgical care. Pediatric surgical outreach program can achieve reduction in surgical disease burden of children in the rural areas.

\section{Introduction}

Day case surgeries refer to elective procedures performed on the day of admission and the patient discharged home the same day. Other terms synonymous with day case surgery include ambulatory surgery, same day surgery, and outpatient surgery. In many countries of the world, there is a steady increase in the rates of day case surgery [1]. Healthcare providers, health policy makers and patients have appreciated the benefits of day case surgeries [1]. In developing countries, not all patients who need surgery can access it. The reasons for this can be summarized as 'barriers of surgery'. These barriers of surgery include physical, financial and low socio-economic status $[2,3]$. The inaccessibility to surgical treatment is worse in children due to paucity of trained pediatric surgeons and lack of specialist hospitals where surgical care can be offered especially in rural areas. Medical outreach, including surgeries, brings treatment to the domains of the children at no cost to the patients' caregivers such that the barriers of surgery are reduced, at least to an extent. Medical outreach forms an avenue for free dissemination of medical treatment to those who otherwise may not afford it. The purpose of study was to evaluate our experience in carrying out pediatric day case surgeries during medical outreaches in the rural settings of Enugu, south east Nigeria.

\section{Patients and Methods}

This was a retrospective study of children that had day case surgeries during surgical outreach programs. The medical 
outreaches were organized and funded by different medical associations in Enugu, Nigeria. The medical associations are: National Association of Resident Doctors (NARD); Medical and Dental Consultant Association of Nigeria (MDCAN); Christian Medical and Dental Association (CMDA), Christian Health Association of Nigeria (CHAN) and Association of Public Health Physician of Nigeria (APHPN). The surgical care was at no cost to the patients. This study covered a 5-year period, from January 2015 to December 2019. A total of 10 outreach programs were organized during this period. Each outreach program lasted for only one day, from $9 \mathrm{am}$ to $5 \mathrm{pm}$. All the outreach programs took place in the rural areas of Enugu State. Enugu is located in south eastern part of Nigeria which according to the 2016 estimates of the National Population Commission and Nigerian National Bureau of Statistics, has a population of about 4 million people and a population density of $616.0 / \mathrm{km}^{2}$. Majority of the population reside in the rural areas.

\section{Preparatory Protocol}

The community leaders and village heads were informed about the medical outreach program. The community heads in turn inform and mobilize members of the community. The venue for the outreach was the district/general hospitals located in the respective rural areas. There were pre-outreach visits, by the medical team, to the venue of the outreach in which local volunteers were educated on what their duties will be. There were also discussions and collaborations between medical team at the health centers and outreach medical team. The outreach team consisted of specialist pediatric surgeon, other medical specialists, resident doctors, anesthetists, nurses, pharmacists, medical students and other support staff. Drugs and sterile surgical instruments were provided by the visiting outreach team.

\section{Outreach Day}

On arrival at the venue, the villagers were already gathered. Pre-operative evaluations were performed clinically and informed consent obtained. Pre-operative investigations were not done. The surgeries were performed by resident doctors and a consultant pediatric surgeon. The anesthesia was conducted by doctor anesthetist. All the surgeries were performed under general anesthesia.

\section{Post-Operative Management}

Post-operative care was handled by the medical personnel's resident at the rural areas. This basically involves removal of wound dressing and wound dressing. Analgesics and antibiotics were given for 5 days. Communications were maintained with local health personnel.

\section{Data Collection}

The following data were collected: Gender, age, duration of symptoms, diagnosis, operative procedure performed, outcome of treatment and complications of treatment.

\section{Data Analysis}

IBM Statistical Package for Social Science (SPSS) for windows version 23 (IBM Corp., Armonk, NY) was used for data entry and analysis. Data were expressed as percentages and medians.

\section{Ethics Approval}

This was not an institutional based study. The need for ethical clearance does not arise.

\section{Results}

\section{Patient's Demography}

During the period of the study, a total of 184 surgeries were performed at the outreach programs, out of which 108 cases (58.7\%) were pediatric day case surgeries. There were 81 (75\%) males and $27(25 \%)$ females, with a male to female ratio of 3:1. Details are depicted in (Table 1).

Table 1: Demographic profile of the patients.

\begin{tabular}{|c|c|}
\hline Gender & $81(75 \%)$ \\
\hline Male & $27(25 \%)$ \\
\hline Female & 54 months (range: $10-72$ months) \\
\hline Median age of the patients & 7 months (range: $2-36$ months) \\
\hline Median duration of the problem
\end{tabular}

\section{Patient's Diagnosis}

Diagnosis of the patients is shown in (Table 2).

Table 2: Diagnosis of the patients.

\begin{tabular}{|c|c|c|}
\hline Diagnosis & Number & Percentage \\
\hline Hernia & 32 & 29.6 \\
\hline Hydrocele & 43 & 39.8 \\
\hline Undescended testis & 22 & 20.4 \\
\hline Lumps/masses & 11 & 10.2 \\
\hline Total & 108 & 100 \\
\hline
\end{tabular}

\section{Operative Procedure Performed}

Seventy five (69.4\%) patients had herniotomy, 22 (20.4\%) patients had orchidopexy and $11(10.2 \%)$ patients had excision of masses.

\section{Outcome and Post-Operative Complications}

Ninety eight $(90.7 \%)$ patients had uneventful recovery. Six (5.6\%) patients had surgical site infection and 4 (3.7\%) had recurrence of their lesion. There was no mortality.

\section{Discussion}

Healthcare services in the rural areas of Nigeria are provided by the local government-run primary health centers which are manned by nurses and paramedics [4]. The 2 tertiary hospitals in Enugu State are located in state capital which is far from the rural dwellers. Medical outreach programs extend the reach of 
specialist healthcare through activities such as health education and provision of health services. Pediatric surgical diseases do not receive the attention it deserves [5]. Although the range of surgeries that can be performed during medical outreach is limited, day case surgeries can be safely performed in children. Some of the international health organizations that offer pediatric surgery outreach programs include Doctors Without Borders, International Medical Corps, Project Hope, Global Health Council etc. More day case surgeries were performed in children than in adults during the outreach programs. The exact reason for this is not clear but might be explained by the larger number of children who presented during the outreach programs and the differences in pathologies between children and adults. It is interesting to note that pediatric surgeons are at the forefront of the development of day case surgery [6]. In children, the benefits of day case surgery are clear and this has spread to other specialties [6]. However, in urological surgeries, more adults may participate in day care surgeries [7]. In the present study, more males were operated on than female. This finding is consistent with the report of other studies on pediatric day cases $[8,9]$. The median age of our patients are in line with the findings of similar studies $[9,10]$, while it varies with the report of other studies $[11,12]$. Differences in the ages of the patients depend on the ages of the children who presented during the outreach. The children who were operated upon on during the outreach program had their symptoms for a variable length of time. Ojo et al. reported that the symptoms in their patients were long in duration and huge in size [3].

Poverty, ignorance and unavailability of specialist care may have affected the long duration of their surgical lesions before treatment. The range of pediatric surgeries that can be performed during outreaches vary from one setting to another. The duration of the medical outreach may also affect the complexity of surgeries that can be performed. In the present study, only day cases were performed because the outreach program lasted for only one day in each centre. Herniotomy was the most common performed surgical procedure. This is in agreement with the report of other researchers $[11,13]$. Other procedures performed include orchidopexy for undescended testis and excision of masses. This is similar to the findings of other studies [8,11]. Procedures such as Sistrunk operations, circumcisions, release of tongue tie and syndactyly could also be performed as day cases $[8,10]$. The overall outcome of the outreach programs was good. Majority of the patients did not develop any complications and went home the same day. A few of the patients had surgical site infection. The incidence rate of surgical site infection following day case surgeries ranges from $0.41 \%$ to $10 \%$. $[10,14,15]$. The environment is an important factor in the etiology of surgical site infection. The environment of the district hospitals may have contributed to the rate of surgical site infection.

\section{Conclusion}

Pediatric day case surgeries performed during outreach programs is of immense benefit to people in the rural communities. Although the operating environment is suboptimal, more of such outreaches will offer specialist care services to children in the rural area who otherwise could not afford such services. Pediatric surgical outreach program can achieve reduction in surgical disease burden of children in the rural areas.

\section{Authors' Contribution}

The author contributed solely to this article.

\section{Availability of Data and Materials}

Data is available with the author and can be provided on request.

\section{Financial Support}

None.

\section{Conflict of Interest}

The author declares that there is conflict of interest.

\section{Ethical Approval}

Not applicable.

\section{Consent for Publication}

Not applicable.

\section{References}

1. Kulkami S, Harsoor SS, Chandrasekar M, Bhaskar SB, Bapat J, et al. (2017) Consensus statement on anaesthesia for day case surgeries. Indian Journal of anaesthesia 61(2): 110-124.

2. Awoyemi TT, Obayelu OA, Opaluwa HI (2011) Effect of distance on utilization of health care services in rural Kogi State, Nigeria. Journal of Human Ecology 35(1): 1-9.

3. Ojo E, Okoi E, Umoiyoho AJ, Nnamonu M (2013) Surgical outreach program in poor rural Nigerian communities. Rural and Remote Health 13(1): 2200.

4. Thomas G, Richards FO, Eigege A, Dakum NK, Azzuwut MP, et al. (2009) A Pilot Program of Mass Surgery Weeks for Treatment of Hydrocele Due to Lymphatic Filariasis in Central Nigeria. American Journal of Tropical Medicine and Hygiene 80(3): 447-451.

5. Manickchund Y, Hadley GP (2017) Paediatric surgery outreach: analysis of referrals to a tertiary paediatric surgery service to plan an outreach programme Kwa-Zulu Natal, South Africa. Tropical Doctor 47(4): 305311.

6. Upadhyaya M, Lander A (2013) Day-case surgery in children. Surgery 31(3): 140-144.

7. Takure AO, Shittu OB, Okeke LI, Olapade Olaopa OE, Adebayo SA (2010) Daycase urology at Ibadan, Nigeria. a ten year review. Pan African Medical Journal 6: 13

8. Bittmann S, Ulus H (2004) Parent satisfaction with paediatric daysurgery: a questionnaire-based study. Journal of Ambulatory Surgery 11: 3-5. 
9. Imarengiaye C, Osifo D, Tudjegbe S, Evbuomwan I (2009) Anaesthesia for Ambulatory Paediatric Surgery: Common techniques and complications. West African Journal of Medicine 28(5): 304-307.

10. Kache SA, Sale D, Ajah JL, Makama JG (2018) Paediatric day-case surgery in a new paediatric surgical unit in Northwestern Nigeria. African Journal Paediatric Surgery 15(2): 97-99.

11. Abdul Rahman LO, Kolawole IK, Adeniran JO, Nasir AA, Taiwo JO, et al. (2009) Pediatric day case surgery: experience from a tertiary health institution in Nigeria. Annals of African Medicine 8(3): 167-177.

12. Adenekan AT (2014) Perioperative blood glucose in a paediatric daycase facility: Effect of fasting and maintenance fluid. African Journal Paediatric Surgery 11(4): 317-322

\section{ISSN: 2574-1241}

DOI: 10.26717/BJSTR.2021.34.005500

Chukwubuike Kevin Emeka. Biomed J Sci \& Tech Res

(c) (9) This work is licensed under Creative

Submission Link: https://biomedres.us/submit-manuscript.php
13. Akpoduado DD, Imarengiaye C, Edomwonyi NP (2016) Caudal analgesia for herniotomy: Compparative evaluation of two dose schemes of bupivacaine. Nigerian Journal of Clinical Practice 20(2): 205-210.

14. Kekre G, Dikshit V, Kothari P, Mudkhedkar K, Gupta A, et al. (2018) Incidence of wound infection in common paediatric day care surgeries following a no-antibiotic protocol: a viable recommendation for a public hospital in India. International Journal of Surgery 5(5): 1729-1732.

15.Zamkowski MT, Makarewicz W, Ropel J, Bobowicz M, Kakol M, et al. (2016) Antibiotics prophylaxis in open inguinal repair: a literature review and summary of current knowledge. Videosurgery and other Miniinvasive Techniques 11(3): 127-136.

$\begin{array}{ll}\text { BIOMEDICAL } & \text { Assets of Publishing with us } \\ \text { RESEARCHES } & \text { - Global archiving of articles } \\ \text { - Immediate, unrestricted online access } & \text { - Rigorous Peer Review Process } \\ & \text { - Authors Retain Copyrights } \\ \end{array}$

